\title{
Osteoporosis Prevention Exercise Effects to Bone Density in Children with Thalassemia
}

\author{
Andreas Arie Widiadiaksa Waluyojati, Marietta Shanti Prananta, Marina Annete Moeliono \\ Department of Physical Medicine and Rehabilitation, Faculty of Medicine, Universitas Padjadjaran-Dr. Hasan \\ Sadikin General Hospital, Bandung
}

\begin{tabular}{|c|c|}
\hline \multirow[t]{3}{*}{ Abstract } & $\begin{array}{l}\text { Objective: To discover recommendation of osteoporosis prevention exercise } \\
\text { (OPE) for children with thalassemia. }\end{array}$ \\
\hline & $\begin{array}{l}\text { Methods: This study was conducted in the period of April-June } 2017 \text { by } \\
\text { using quasi experimental and pretest-posttest designs. Eleven thalassemia } \\
\text { patients who were the members of a thalassemia patient foundation and } \\
\text { an association of parents of thalassemia patients, Yayasan Thalassaemia } \\
\text { Indonesia and Perhimpunan Orangtua Penderita Thalassemia Indonesia, } \\
\text { were enrolled in the study as the subjects. Sample calculation was carried } \\
\text { out by using consecutive sampling method. The subjects were given OPE } \\
\text { intervention } 2 \text { times per week during } 12 \text { weeks with } 35 \text { minutes of each } \\
\text { session. BMD of spinal lumbar examination was performed before and after } \\
\text { practicing OPE. Collected data were analyzed statistically by using paired t } \\
\text { and Wilcoxon tests with p value }<0.05 \text {. }\end{array}$ \\
\hline & $\begin{array}{l}\text { Results: After the intervention, BMD value of } \mathrm{L} 1, \mathrm{~L} 2 \text {, and } \mathrm{L} 3 \text { segments did not } \\
\text { improve significantly while BMD value of L4 segment and average Z-score } \\
\text { showed significant improvement }(\mathrm{p}<0.05) \text {. }\end{array}$ \\
\hline $\begin{array}{l}\text { Received: } \\
\text { July 13, } 2018\end{array}$ & $\begin{array}{l}\text { Conclusions: Osteoporosis prevention exercise can improve BMD in children } \\
\text { with thalassemia. Continuous OPE program can be recommended for children } \\
\text { with osteoporosis-induced thalassemia. }\end{array}$ \\
\hline $\begin{array}{l}\text { Revised: } \\
\text { September 13, } 2018\end{array}$ & $\begin{array}{l}\text { Keywords: Bone mineral density, osteoporosis, osteoporosis prevention } \\
\text { exercise, thalassemia, Z-score }\end{array}$ \\
\hline $\begin{array}{l}\text { Accepted: } \\
\text { September 17, } 2018\end{array}$ & $\begin{array}{l}\text { pISSN: 2302-1381; eISSN: 2338-4506; http://doi.org/10.15850/ijihs.v6n2.1349 } \\
\text { IJIHS. 2018;6(2):84-90 }\end{array}$ \\
\hline
\end{tabular}

\section{Introduction}

Thalassemia is defined as hemoglobinopathies of autosomal recessive condition, genetically inherited and is characterized by a decrease in the polipeptida globin chain synthesis in hemoglobin. ${ }^{1}$ It is considered as an identical genetic abnormality in the form of a singleallele gene disorder in alleles that play a role in hemoglobin production. ${ }^{2}$ There are two categories of thalassemia, alpha and beta types. Beta thalassemia can be further divided into two types, major and minor. Beta thalassemia

Correspondence:

Andreas Arie Widiadiaksa Waluyojati, Department of Physical Medicine and Rehabilitation, Faculty of Medicine, Universitas Padjadjaran-Dr. Hasan Sadikin General Hospital, Bandung

Jl. Pasteur No. 38, Bandung, Indonesia

e-mail: arie.widiadiaksa@gmail.com major occurrences are found in various areas including Mediteranian, Middle East, Central Asia, North Africa, and Souh America. ${ }^{2}$

In Indonesia, thalassemia affects $3-5 \%$ of the total population. ${ }^{3}$ Data published in 2014 by Yayasan Thalassaemia Indonesia (Indonesia Thalassemia Foundation) and Perhimpunan Orangtua Penderita Thalassemia Indonesia (Indonesia Parent Association of Thalassemia Children) has described that the number of thalassemia patients has considerably rising wit 2,500 out of 6,647 thalassemia patients ae children. ${ }^{3}$

Several chronic diseases and complications are commonly found in thalassemia patients such as disorders of sex development (DSD), growth hormone disorders, osteoporosis, and osteopenia. $^{2,4}$ Some studies stated thalassemia occurences in children are often followed by osteopenia and osteoporosis, leading to 
bone mineral density (BMD) decrease. This condition becomes a serious problem for thalassemic young adult patients as it may cause a higher risk for fractures due to the fact that osteopenia and osteoporosis prevalence is $50 \%$ the thalassemia patients. The prevalence of fracture is high in thalassemia patients with more than $50 \%$ of beta thalassemia major patients experience fracture. . $^{2,5,6}$

A previous study has stated that the upper extremity fractures are the most dominant fractures in thalassemia patients, which is followed by spinal and pelvis compression fractures. The spinal and pelvis compression fractures typically found in thalassemia causes back pain, leading to decreased quality of life (QoL). ${ }^{8}$ Hence, proper treatments should be given to the patients to reduce the risk of fractures that is caused by decreased BMD.

Decreased BMD can be prevented through practicing weight-bearing aerobic exercise, with or without resistance training. ${ }^{9}$ Several studies have conducted investigations on the relationship between the aerobic exercise and weight-bearing exercise with treadmill and resistance trainings on hemophilia patients as the subjects. It was shown that a significant BMD increase was seen after this intervention was performed. ${ }^{10,11}$

Having been widely socialized since 1991 in Indonesia to elderly, osteoporosis prevention exercise (OPE) can improve several aspects, such as muscular flexibility, muscular strength, bone strength, endurance, balance, and also coordination and is considered as low impact aerobic. ${ }^{12}$ The OPE impact investigation had been conducted and the results determined practicing OPE can maintain BMD and reduce osteoporosis risk in elderly. ${ }^{12}$ This study aimd to examine the effect of OPE to BMD in children with thalassemia.

\section{Methods}

This study included children with thalassemia major diagnosis who lived in Bandung, West Java, Indonesia as the subjects. The subjects received routine blood transfusion in hospitals. Inclusion criteria in this study were children aged 10-14 years, diagnosed as suffering from thalassemia major, able to communicate, able to stand and walk without supports, able to do daily activities without supports, receiving regular blood transfusion at least once in a month, receive regular iron chelation therapy, willing to be included in the study, and gain permission from the parents.
The exclusion criteria included pain with NRS $>4$, osteoporosis, musculoskeletal deformity, fracture history, and a Berg balance scale of $<41$. Meanwhile, dropout criteria were not practicing exercise $>18$ times and unwilling to continue the exercise.

Sample calculation formula was used due to discover total samples for paired category and numeric analyses. Based on the sampling method, the total minimal sample size was 11. Sampling was performed by using consecutive sampling method with statistical examination with a confidence interval of $95 \%$ and power test of $95 \%$.

The method used in the study was quasi experimental because the experiment did not include a control group. Quasi experimental method is suitable for one of the three terms of true experiment design: random sampling, inclusion of control group, and inclusion of intervention. Pretest-posttest design was used by examining before and after the intervention. The data were collected through anamnesis, physical examination, and BMD assessment. ${ }^{13}$ The variables analyzed in the study were OPE (independent variable), BMD (dependent variable), physical activity, body mass index/ BMI, as well as nutrition intake (confounding variable).

Materials and devices used in this study were sphygmomanometer for childdren with riester brand, stethoscope with littman brand, pulse oxymetri Breuer brand, height and weight measurement device, 250 grams load, music players for OPE, and oxygen tube. Dual energy X-ray absorptiometry (DEXA) scanner was used to assess BMD.

Subjects received OPE intervention twice a week for 12 weeks. The intervention was guided by training instructures and supervised by medical doctors. In order to encourage the subjects, education related to osteoporosis in thalassemia, osteoporosis prevention, and physicosocial knowledge was given monthly.

Either the subjects or the parents signed the informed consent describing about willingness to participate in the study and were asked to fill questionnaires to assess daily activities, regularity of receiving blood transfusion and iron chelation therapy.

Measurements of the blood pressure, pulse, and oxygen saturation were performed while the in sitting position. Weight and height were measured to calculate BMI. Afterwards, body balance was measured by using Berg Balance scale. Assessment of initial BMD was conducted by using DEXA scan between the lumbars before the intervention. Repeated 
BMD assessment was later conducted by using DEXA after week 12.

Subjects practiced OPE for 35 minutes in each exercise which contained several steps as follows: (a) warming up (5 minutes), dynamic and static streches (5 minutes), training I (10 minutes), weight training II (10 minutes), and cooling down (5 minutes). ${ }^{12}$ The load used during the exercise was 250 grams held by each hand. To obtain maximal results, pulse was monitored at the start and the end of every exercise step. The subjects were informed to stop excercising if they feel problems such as pain, asphyxia, nausea, dizziness, exhaustion, and uncomfortable feelings.

Categorical data were examined using Mc. Nemar test. Before the statistical tests were performed, numerical data was examined for their normality test using Shapiro Wilks test due to the fact that the number of the total data was less than 50. Another statistical test was used to compare the result characteristics before and after the intervention, i.e. paired t-test. A significant value was represented with $\mathrm{p} \leq 0.05$ and non-significant value was $\mathrm{p}>0.05$.

The study was conducted in the period of April-Juni 2017 and held in the Teaching Hospital Building of the Faculty of Medicine, Universitas Padjadjaran, Bandung and Rumah Singgah Sahabat Talassemia, Bandung. All data and information were kept confidential. Ethical approval for this study was obtained from the Health Research Ethic Committee, Faculty of Medicine, Universitas Padjadjaran.

\section{Results}

The subjects in this study were 11 children with thalassemia major aged 10-14 who met the inclusion criteria. Basic characteristics of the subjects was represented (Table 1).The subjects' characteristics were examined based on age, sex, weight, height, BMI, Berg Balance Scale in numbers and percentage.

The average age of the subjects in this study was $12.25 \pm 1.650$ with predominantly female subjects. The average weight was $30.95 \pm 8.647$ and average height was $137.90 \pm 12.895$. Data were normally distributed and could be analyzed by using paired $t$ test. Bone mineral density comparison between L1, L2,L3, L4 segments, lumbar, and Z-score of the subjects were presented (Table 2). Since the total subjects were 11 children, BMD of the L1, L2, and L3 segments was $p>0.05$. This determined that no significant improvement was seen.
Table 1 The Subjects' Characteristics

\begin{tabular}{lc}
\hline \multicolumn{1}{c}{ Variables } & $\mathbf{n = 1 1}$ \\
\hline Age & $12.25 \pm 1.650$ \\
Mean \pm Std & 12.5 \\
Median & $10-14$ \\
Range (min-max) & \\
Sex & 7 \\
Male & 13 \\
Female & \\
Weight & $30.95 \pm 8.647$ \\
Mean \pm Std & 30 \\
Median & $20-51$ \\
Range (min-max) & \\
Height & $137.90 \pm 12.895$ \\
Mean \pm Std & 136.5 \\
Median & $122-173$ \\
Range (min-max) & \\
Body Mass index & $15.92 \pm 1.785$ \\
Mean \pm Std & 15.985 \\
Median & \\
Range (min-max) & \\
\hline
\end{tabular}

Note: Categorical data were presented by total/frequency and percentage while numerical data were presented by average, median, standard deviation, and range

Bone mineral density improvement was found in L4 segment from average $0.56 \pm 0.139$ before exercising to become $0.60 \pm 0.129$ after exercising with $p$ value $<0.05$. The lumbar spine average value improved from 0-4.00 \pm 1.449 before exercising to become $-3.81 \pm 1.376$ after exercising with $\mathrm{p}<0.05$ (Fig).

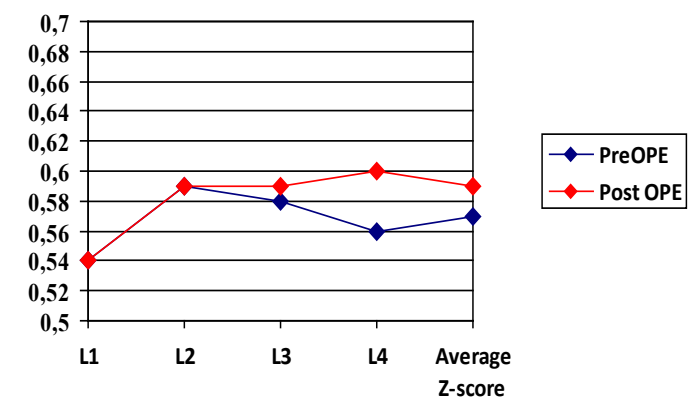

Fig. Bone Mineral Density Value pre OPE and Post OPE 
Table 2 Bone Mineral Density Value Comparison between L1. L2, L3, L4 Segments

\begin{tabular}{|c|c|c|c|}
\hline \multirow{2}{*}{ Variables } & \multicolumn{2}{|c|}{ Groups } & \multirow{2}{*}{ p Value } \\
\hline & Pre $n=11$ & Post $n=11$ & \\
\hline Segment L1 & & & 0.982 \\
\hline Mean \pm Std & $0.54 \pm 0.123$ & $0.54 \pm 0.136$ & \\
\hline Median & 0.513 & 0.515 & \\
\hline Range (min-max) & $0.36-0.74$ & $0.37-0.77$ & \\
\hline Segment L2 & & & 0.923 \\
\hline Mean \pm Std & $0.59 \pm 0.147$ & $0.59 \pm 0.130$ & \\
\hline Median & 0.560 & 0.563 & \\
\hline Range (min-max) & $0.39-0.91$ & $0.40-0.84$ & \\
\hline Segment L3 & & & 0.278 \\
\hline Mean \pm Std & $0.58 \pm 0.156$ & $0.59 \pm 0.151$ & \\
\hline Median & 0.542 & 0.570 & \\
\hline Range (min-max) & $0.32-0.92$ & $0.32-0.86$ & \\
\hline Segment L4 & & & $0.034^{* *}$ \\
\hline Mean \pm Std & $0.56 \pm 0.139$ & $0.60 \pm 0.129$ & \\
\hline Median & 0.553 & 0.603 & \\
\hline Range (min-max) & $0.40-0.86$ & $0.41-0.86$ & \\
\hline Average BMD & & & 0.134 \\
\hline Mean \pm Std & $0.57 \pm 0.141$ & $0.58 \pm 0.134$ & \\
\hline Median & 0.525 & 0.551 & \\
\hline Range (min-max) & $0.37-0.87$ & $0.38-0.83$ & \\
\hline
\end{tabular}

Note: $\mathrm{p}$ value of numerical data were analyzed by using paired $t$ test if the data were normally distributed.

*Statistically significant $\mathrm{p}<0.05$

\section{Discussion}

Several studies have reported thatchildren with thalassemia are prone to osteoporosis. ${ }^{6,10,14}$ In the present study, a value of BMD that was less than 2.5 SD of BMD reflects that the subject had low BMD or in the range of osteopenia based on the inclusion criteria. Neither primary nor secondary osteoporosis patients were enrolled in the study. Thalassemia major becomes a main factor of secondary osteoporosis found in the subjects. The subjects with secondary osteoporosis were not included in the study due to different condition from osteoporosis generally found in elderly. Estrogen deficiency causes an increase in the osteoclastogenesis activity within bone metabolism. Therefore, thalassemia patients commonly suffer from estrogen disorder. ${ }^{15,16}$ Other factors can also influence BMD values including, among others, endocrine disorders, kidney or hematological problems that is caused by congenital diseases, metabolic problems, and medical management to osteoporosis patients or commonly called secondary osteoporosis. ${ }^{15}$

Both male and female subjects aged 10-14 years were enrolled in this study. The subjects had entered puberty period since all female subjects had menstruation period. Menstrual cycle becomes one of several factors which can influence bone metabolism. Based on natural process, menstruation is caused by dynamical condition between estrogen and progesteron. A study has described that bone resorption activity improvement occurs during menstrual cycle. $^{16}$ Estrogen becomes protector within 
body which can maintain inner stability from many diseases. Nevertheless, estrogen ability decreases after women entering menopause. Fifty percent of women with thalassemia do not have menstrual period leading to earlier estrogen protection loss. ${ }^{16}$

Bone metabolism phase including bone remodeling occurs during life but peak bone mass in normal people occurs until 20-30 years old. After entering this period, the bone remodeling in males and females gradually decreases while the catabolic process occurs. The immediate bone resorption increases in females when entering the menopause period. Since females not having menstrual period as found in thalassemia patients, the absence of estrogen from the beginning in life causes problems in the bone remodeling phase and the catabolic and anabolic imbalance. However, normal females face bone resorption activity starting form menarche to menopause ${ }^{16}$ The absence of menstrual period can affect the SOP results caused by physical and psychological changes. In this study all subjects had regular menstrual cycle, showing that no estrogen disorder occurred. However, further estrogen examination of the subjects was not performed in the study.

Weight-bearing exercise will increase the BMD in people of all age groups if they do not suffer from osteoporosis. Therefore, during the immature bone period, impact of weightbearing exercise can influence bone growths and developments. Weight-bearing exercise given to the subjects in pubertal growth spurt can increase BMD due to the immature bone condition. The exercise given to young adult subjects can improve size, shape, and structure of bones. ${ }^{17}$

The subjects in this study received blood transfusion once in a month and iron chelation therapy. Regular transfusion and iron chelation therapy were done to reduce iron toxicity effect and chronic anemia toward BMD. Chronic anemia influences bone metabolism including vitamin D, estrogen receptor, and collagen formation. ${ }^{18,19}$ Beside chronic anemia, another problem found is iron overload. Iron overload in tissues and bones causes growth failure and bone abnormality. Iron chelation therapy can reduce ferritin level in tissues and blood. Iron toxicity to osteoblasts and iron chelation agents causes decreased BMD in thalassemia patients. ${ }^{6}$ Receiving blood transfusion and iron chelation therapy are proper treatments among many factors which can maintain BMD in children with thalassemia. Osteoporosis prevention exercise was given although the subjects receiving blood transfusion and iron chelation therapy in order to improve and maintain BMD.

The assessment of BMD was performed by DEXA in the subjects' spinal lumbar due to its beneficial characteristics including immediate use, high accuracy, low radiation, and high precision. In addition, it is considered as the most suitable BMD assessment method for children. ${ }^{20}$ The assessment results by using DEXA were Z-score and T-score, however, in this study the data used was Z-score. Z-score is a comparison between bone density based on the assessment and bone density based on age.

Bone mineral density assessment by using DEXA can be performed in seveal area such as spine, pelvis, and wrist. However, in this study theassessment was performedonly in the spinal lumbar. There were several reasons that the assessment which had been performed. First, spinal fracture incidence ratio was 13-36\% in thalassemia patients. The BMD assessment values in thalassemia patients were lower in the spine which were approximately $62 \%$ and $35 \%$ in pelvis. ${ }^{4,8}$ Second, spine is the center of body weight-bearing which can be a main focus for monitoring improvements after weightbearing exercise. The spinal lumbar becomes the main focus of all spinal movements. Third, the spine is primary trabecular bone which is an area mostly influenced by enlarged bone marrow occurrence. ${ }^{4}$ The three conditions are considered the major causes that the spine having the lowest BMD value when compared to the results discovered in other bone areas. This condition determines that DEXA scan in the lumbar is the most appropriate effort to examine the BMD. The Bone mineral density assessment results in the spinal lumbar were obtained from L1-L4 segments. Therefore, L5 segment was not investigared due to potential influence by density value from the pelvis.

This study discovered lower BMD of the subjects before the intervention. The lower BMD value leads to a higher risk for spinal fracture. ${ }^{6}$ Lower BMD value in the thalassemia patients is influenced by many factors. The factors include liver disease, diabetes mellitus, hyperthyroidism, growth hormone and insulin growth factor deficiency, inhibited sexual maturity, ineffective haematopoiesis followed by enlarged bone marrow, parathyroid gland dysfunction, iron toxicity to osteoblast, iron chelating agent toxicity, and liver diseases. ${ }^{4-8}$ However, only several influencing factors related to lower BMD value were included in this study. 
Average BMI of the subjects in this study was low (15.92 \pm 1.785$)$. This finding is similar to another study conducted in Pakistan stated BMI of children with thalassemia aged 2-15 years was low. ${ }^{20}$ Several factors which influence lower BMD in children with thalassemia are multiple endocrinopathies, iron deficits in main organs, and low nutrition intake.

No significant BMD improvement in the overall lumbar segment was discovered in this study. However, significant improvement was discovered in L4 segment and Z-score. The data revealed that practicing OPE can increase BMD in children with thalassemia. Improvements were also influenced by exercise frequency and duration.

DifferentBMDvaluewasfound in L4 segment of the spine after 12 week intervention. This finding is in accordance with several studies which described that improvement occurs because L4 and L5 segments of spinal lumbar between center pivot point which becomes the center of all spinal movements in sagittal for flection and extension movements. ${ }^{7,10,17}$ While practicing OPE, axial load and shear stress

\section{References}

1. Galanello R, Origa R. Beta-thalassemia. Orphanet] Rare Dis [serial on the internet]. 2010 May [cited 2017 Nov 20];5(11):[about 15p.]. Available from: https://ojrd.biomedcentral. com/articles/10.1186/1750-1172-5-11.

2. Yaman A, Isik P, Yarali N, Karademir S, Cetinkaya $\mathrm{S}$, Bay A, et al. Common complications in Betathalassemia patients. Int J Hematol Oncol. 2013;23(3)193-9.

3. Yayasan Thalassaemia Indonesia.Data penderita thalassemia di Indonesia. [cited 2018 Jan 6]. Available from: https://www. thalassaemia-yti.org/

4. Wong LP, George E, Tan J-AMA. Public perceptions and attitudes toward thalassaemia: Influencing factors in a multi-racial population. BMC Public Health [serial on the internet]. 2011 Mar [cited 2017 Nov 20];11(193):[about 9p.]. Available from: https://www.ncbi.nlm. nih.gov/pmc/articles/PMC3076274/.

5. Chapin JC, Vogiatzi M, Kleinert D, DeFilippis E, Christos P, Giardina P. Fracture prevalence in adults with transfusion-dependent thalassemia is related to osteoporosis and age. Blood [serial on the internet]. 2014 [cited 2017 Dec 3];124(21):[about 3p.]. Available from:http:// force continuously occur in the spine. Shear stress is caused by gravitation and muscular contraction effects.

This study has several limitations to be consiered. The hormonal functions, nutrition intake, and activity levels in assessing subjects' BMD were not investigated. Further studies can be conducted by investigating nutrition intake functions within body, and also daily activities performed by the subjects.

As the intervention was held in a centralized venue, this condition might cause higher number of dropouts. Another factor of higher number of dropouts was the distance of the venue and inflexible time of the intervention for students. Alternative ways should be discovered in order to obtain higher total samples such as availability of nearby venue in each community. In conclusion, increased BMD in the lumbar was discovered in children with thalassemia after practicing the OPE session. Continuous OPE program becomes suitable effort due to prevent osteoporosis in children with thalassemia. www.bloodjournal.org/content/124/21/4902.

6. Wong P, Fuller PJ, Gillespie MT, Milat F. Bone disease in thalassemia: a molecular and clinical overview. Endocrine Rev. 2016;37(4):320-46.

7. Vogiatzi MG, Macklin EA, Fung EB, Cheung AM, Vichinsky E, Olivieri $\mathrm{N}$, et al. Bone disease in thalassemia: a frequent and still unresolved problem. J Bone Min Res. 2009;24(3):543-57.

8. Haidar R, Mhaidli H, Musallam KM, Taher AT. The spine in $\beta$-thalassemia syndromes. Spine. 2012;37(4):334-9.

9. Body JJ, Bergmann P, Boonen S, Boutsen $\mathrm{Y}$, Bruyère $\mathrm{O}$, Devogelaer $\mathrm{J}-\mathrm{P}$, et al. Nonpharmacological management of osteoporosis: a consensus of the Belgian Bone Club. Osteoporosis Int. 2011;22(11):2769-88.

10. Eid MA, Ibrahim MM, Aly SM. Effect of resistance and aerobic exercises on bone mineral density, muscle strength and functional ability in children with hemophilia. Egypt J Med Human Genetics. 2014;15(2):139-47.

11. El-Shamy S. Effect of whole body vibration training on quadriceps strength, bone mineral density, and functional capacity in children with hemophilia: a randomized clinical trial. J Musculoskelet Neuronal Interact. 
2017;17(2):19-26.

12. Widianti, Atikah. Senam kesehatan. Yogyakarta: Muha Medika; 2010.

13. Sudigdo S. Dasar-dasar metodologi penelitian klinis. $4^{\text {th }}$ ed. Jakarta: Sagung Seto; 2011.

14. Mohseni F, Mohajeri-Tehrani M, Larijani B, Hamidi Z. Bone density changes in thalassaemic patients with age and time period. HKJ Paediatr. 2016;21(4):257-61.

15. Lorentzon M, Cummings S. Osteoporosis: the evolution of a diagnosis. J Internal Med. 2015;277(6):650-61.

16. Chiu KM, Ju J, Mayes D, Bacchetti P, Weitz $\mathrm{S}$, Arnaud CD. Changes in bone resorption during the menstrual cycle. J Bone Miner Res. 1999;14(4):609-15.

17. Behringer M, Gruetzner S, McCourt M, Mester J. Effects of weight-bearing activities on bone mineral content and density in children and adolescents: a meta-analysis. J Bone Miner Res.
2014;29(2):467-78.

18. Toumba M, Skordis N. Osteoporosis syndrome in thalassaemia major: an overview. J Osteoporosis [serial on the internet]. 2010 Jun [cited 2002 Aug 12];2010(2010):[about 7p.]. Available from: https://www.hindawi.com/ journals/jos/2010/537673/.

19. Chan Y-L, Pang L-M, Chik K-W, Cheng JC, Li C-K. Patterns of bone diseases in transfusiondependent homozygous thalassaemia major: predominance of osteoporosis and desferrioxamine-induced bone dysplasia. Pediatr Radiol. 2002;32(7):492-7

20. Shepherd JA, Sommer MJ, Fan B, Powers C, Stranix-Chibanda L, Zadzilka A, et al. Advanced analysis techniques improve infant bone and body composition measures by dual-energy x-ray absorptiometry. J Pediatr. 2017;181(1):248-53. 